\title{
Changes in thromboelastography to predict ecchymosis after knee arthroplasty: a promising guide for the use of anticoagulants: a case control study
}

\author{
Yuelong Chen \\ The First Affiliated Hospital of Chongqing Medical University \\ Leilei Qin \\ The First Affiliated Hospital of Chongqing Medical University \\ Jiawei Wang \\ The First Affiliated Hospital of Chongqing Medical University \\ Xuan Gong \\ Chongqing Zhongshan Hospital \\ Ning Hu ( $\sim$ huncqjoint@yeah.net) \\ The First Affiliated Hospital of Chongqing Medical University
}

\section{Research}

Keywords: TEG, Ecchymosis, Total knee arthroplasty, Thromboelastography

Posted Date: November 19th, 2021

DOI: https://doi.org/10.21203/rs.3.rs-1081662/v1

License: (c) (i) This work is licensed under a Creative Commons Attribution 4.0 International License. Read Full License 


\section{Abstract}

\section{Background}

Ecchymosis is one of the worrisome complications after total knee arthroplasty (TKA) and interferes with functional rehabilitation. Current clinical guidelines do not provide individualized approaches for patients with ecchymoses. In this study, we used thromboelastography (TEG) to determine the coagulation state after TKA and to then explore markers that predict the occurrence of ecchymosis events after TKA.

\section{Methods}

In our cohort, patients were divided into ecchymosis $(n=55)$ and nonecchymosis $(n=137)$ groups according to whether ecchymosis events occurred after TKA. Rivaroxaban $10 \mathrm{mg} / \mathrm{d}$ was taken orally for thromboprophylaxis after surgery. All patients completed TEG testing. Correlation analysis was used to determine the risk factors for ecchymosis after TKA, and receiver operating characteristic (ROC) curves for variables with significant correlation were plotted.

Results

In all, 55 of the 192 patients (28.65\%) developed ecchymosis surrounding the surgical site. Multivariate analysis showed that hidden blood loss $(\mathrm{OR}=1.003$ and $\mathrm{p}=.005)$ and changes in the coagulation index $(\Delta \mathrm{Cl})$ values $(\mathrm{OR}=$ 0.351 and $p=.001$ ) were risk factors for ecchymosis after TKA. Using the Youden index, 0.1805 was determined as the optimal threshold value of $\Delta \mathrm{Cl}$ for predicting the occurrence of ecchymosis, with a sensitivity of $74.55 \%$ and specificity of $72.99 \%$.

\section{Conclusions}

$\Delta \mathrm{Cl}$ is a promising marker as an alarm for the occurrence of ecchymosis after TKA.

Trial registration

Chinese Clinical TrialRegistry, ChiCTR, NO. ChiCTR1800017245. Registered 19 July 2018 - Prospective registered, http://www.chictr.org.cn

\section{Background}

Total knee arthroplasty (TKA) is considered the most effective treatment for end-stage knee osteoarthritis (OA) [1]. Due to the high prevalence of OA, TKA is a fairly common surgery. In the United States, the number of TKAs is projected to increase by $673 \%$ by 2030 [2]. Venous thromboembolism (VTE) is a worrisome complication after TKA[3]. Perioperative anticoagulant prophylaxis has been shown to reduce the incidence of postoperative VTErelated mortality and complications[4]. Evidence-based guidelines recommend that patients undergoing TKA receive oral rivaroxaban for anticoagulant prophylaxis for 14 days[5, 6]. However, postoperative bleeding complications associated with anticoagulation are not uncommon, especially with the widespread use of factor Xa inhibitors, in which the incidence of ecchymosis around the wound is as high as $13 \%[7]$.

The formation of postoperative ecchymosis around the wound is related to the use of anticoagulants[3]. Ecchymosis around the surgical site can prolong the recovery time after TKA and may even lead to reoperation due to periprosthetic infection[8, 9]. At present, there are still no clear guidelines for the balance between postoperative 
anticoagulation and bleeding[10]. The use of anticoagulants should prevent VTE and avoid the occurrence of bleeding events. The monitoring of coagulation function has guiding value for the use of anticoagulants[11]. Routine coagulation tests provide limited information about the quality of coagulation status[12, 13]. Therefore, we need an alarm to predict the occurrence of ecchymosis events around the wound after TKA.

Thrombelastography (TEG) provides a comprehensive evaluation of blood viscoelastic properties and has potential value in predicting postoperative bleeding and thrombotic events[12, 14]. Moreover, previous studies have shown that the change of coagulation index $(\Delta \mathrm{Cl})$ value was a risk factor for patients with ecchymosis after TKA and was expected to guide personalized anticoagulant therapy[6]. Thus, in this study, we sought to (1) explore whether the change in $\triangle \mathrm{Cl}$ can predict ecchymosis after TKA and (2) to calculate the threshold for predicting patients with ecchymosis based on $\Delta \mathrm{Cl}$.

\section{Methods}

From October 2018 to October 2020, we prospectively enrolled patients who were scheduled to undergo primary unilateral total knee arthroplasty (TKA) for knee OA. We excluded patients who (1) underwent bilateral TKA; (2) did not undergo TEG testing; (3) had a history of cardiovascular surgery, VTE or prior anticoagulant therapy; (4) were concomitant with coagulation disorders; (5) were treated with anticoagulation agents other than rivaroxaban; or (6) had incomplete medical records. According to the occurrence of ecchymosis after TKA, the patients were divided into ecchymosis and nonecchymosis groups[6]. The study was registered in the Chinese Clinical Trial Registry (ChiCTR1800017245).

A tourniquet was used intraoperatively, and the tourniquet was loosened before the incision was closed. The anesthesiologist recorded the blood loss during the operation, mainly involving attracting blood from bottles and gauze. No drainage was used. All patients received standard physical therapy and rivaroxaban anticoagulant therapy for 14 days. Rivaroxaban $(10 \mathrm{mg}$ ) was administered once daily starting 12 hours after surgery, monitoring the occurrence of ecchymosis closely and discontinuing rivaroxaban once ecchymosis was observed. Venous blood was collected 1 day before surgery to obtain baseline hematocrit (HCT) and TEG values. The HCT and TEG values were monitored daily postoperatively until the patient was discharged. For discharged patients, investigators followed them up daily to see if there were any ecchymosis events. Once there were ecchymosis events, HCT and TEG tests were completed within 24 hours, and anticoagulation therapy was stopped. TEG tests were performed by a TEG® Hemostasis Analyzer (Hemonetics Corporation, Braintree, MA, USA).

All indicators of TEG (R-time, a-angle, maximum amplitude and $\mathrm{K}$-time) were recorded, and the $\mathrm{Cl}$ was calculated using the formula $\mathrm{Cl}=0.1227(\mathrm{R})+0.0092(\mathrm{~K})+0.1655(\mathrm{MA})-0.0241(\mathrm{a})-5.0220$. We analyzed the $\Delta \mathrm{Cl}$ values for all patients. For patients without ecchymosis after TKA, we analyzed the maximum reduction in $\mathrm{Cl}$ relative to preoperative values; for patients with ecchymosis, we analyzed the $\Delta \mathrm{Cl}$ values between the day of ecchymosis occurrence and preoperatively. The gross[15] equation was used to calculate the volume of human erythrocytes and total blood loss. Then, hidden blood loss was the residual value of the total blood loss during the removal of intraoperative blood loss.

\section{Statistical Analysis}

Statistical analysis was carried out with SPSS 24.0. Comparisons were made between the patients with and without ecchymosis. To clarify the values of factors related to ecchymosis in predicting the occurrence of 
ecchymosis events, the receiver operating characteristic (ROC) curve was established by MedCalc; the area under the ROC curve (AUC) was also calculated. The optimal cutoff values of each index for predicting the occurrence of ecchymosis events and the corresponding specificity and sensitivity were determined by Youden's J statistic. P < 0.05 was considered statistically significant.

\section{Results}

A total of 192 patients who received a unilateral primary TKA were eligible for the study. In all, 55 of 192 patients (28.65\%) developed ecchymosis surrounding the surgical site. There were no statistically significant differences between the two groups in terms of age $(p=.125)$, sex $(p=.480)$, or BMI $(P=.085)$ (Table I). During the follow-up, only 3 patients developed ecchymosis around the wound, which improved after anticoagulant treatment was stopped, and blood samples of these patients were obtained on the day that ecchymosis was observed.

Table I. Demographic data for the study population.

\begin{tabular}{|llll|}
\hline Variables & Non-Ecchymosis group $(\mathbf{n}=137)$ & Ecchymosis group $(\mathbf{n}=\mathbf{5 5})$ & $\mathbf{P}$ Value \\
\hline Age $(\mathrm{y})$ & $67.80 \pm 10.787$ & $65.16 \pm 10.445$ & 0.125 \\
\hline Gender(male/female) & $40 / 97$ & $13 / 42$ & 0.480 \\
\hline Height & $157.82 \pm 7.026$ & $157.48 \pm 6.523$ & 0.764 \\
Weight & $58.242 \pm 9.6932$ & $60.694 \pm 10.1908$ & 0.139 \\
BMl $\left(\mathrm{kg} / \mathrm{m}^{2}\right)$ & $23.355 \pm 3.6025$ & $24.4537 \pm 4.0201$ & 0.085 \\
\hline
\end{tabular}

\section{BMI, body mass index. Variables are expressed as mean \pm SD (standard deviation)}

Total blood loss and hidden blood loss were significantly higher in the ecchymosis group compared to those in the nonecchymosis group (Table II). Compared to preoperative TKA, the average decrease in $\Delta \mathrm{Cl}$ in the ecchymosis group reached $-0.5332 \pm 1.1554$, while the average increase in $\Delta \mathrm{Cl}$ in the nonecchymosis group reached $0.8490 \pm 1.3344$, thereby demonstrating a significant difference between the two groups $(p=.001)$. The levels of total and hidden blood loss were $334.08 \pm 125.71 \mathrm{ml}$ and $319.36 \pm 110.84 \mathrm{ml}$ in the ecchymosis group, which were significantly higher than those in the nonecchymosis group, with $287.8376 \pm 109.4661 \mathrm{ml}(p=.012)$ and $137.3048 \pm 107.5984 \mathrm{ml}(p<0.001)$ for total blood loss and hidden blood loss, respectively. There were no significant differences in operative time $(91.06 \pm 10.406$ minutes vs. $94.69 \pm 16.487$ minutes $)$ or intraoperative blood loss $(31.53 \pm 12.059 \mathrm{ml}$ vs. $32.91 \pm 12.045 \mathrm{ml})$ between the two groups (Table II).

Table II. Comparisons of variables of the Ecchymosis Group and Non-Ecchymosis Group. 


\begin{tabular}{|llll|}
\hline Variables & Non-Ecchymosis group & Ecchymosis group & P Value \\
\hline$\Delta \mathrm{Cl}$ & $0.8490 \pm 1.3344$ & $-0.5332 \pm 1.1554$ & 0.001 \\
\hline Operation time $(\mathrm{min})$ & $91.06 \pm 10.406$ & $94.69 \pm 16.487$ & 0.134 \\
\hline Total blood loss $(\mathrm{mL})$ & $287.8376 \pm 109.4661$ & $334.0836 \pm 125.7136$ & 0.012 \\
\hline Intraoperative blood loss $(\mathrm{mL})$ & $31.53 \pm 12.059$ & $32.91 \pm 12.045$ & 0.475 \\
\hline Hidden blood loss $(\mathrm{mL})$ & $137.3048 \pm 107.5984$ & $319.3564 \pm 110.8418$ & $<0.001$ \\
\hline
\end{tabular}

\section{$\Delta \mathrm{Cl}$, change of coagulation index. Variables are expressed as mean \pm SD (standard deviation)}

We performed multivariate logistic regression analyses on potential risk factors for ecchymosis formation after TKA, including $\Delta \mathrm{Cl}$, hidden blood loss, age, and BMI. The data suggested that $\Delta \mathrm{Cl}(\mathrm{OR}: 0.351,95 \% \mathrm{Cl}: 0.234,0.526$, and $p=.001$ ) and hidden blood loss (OR: $1.003,95 \% \mathrm{Cl}: 1.000,1.007$, and $p=.005$ ) could be independent risk factors for the formation of ecchymosis, in addition to age, BMI, and total blood loss (Table III).

Table III. Risk Factors for ecchymosis after TKA.

\begin{tabular}{|c|c|c|}
\hline Variables & OR (95\% Confidence Interval) & P Value \\
\hline$\Delta \mathrm{Cl}$ & $0.351(0.234,0.526)$ & 0.001 \\
\hline Hidden blood loss (mL) & $1.003(1.000,1.007)$ & 0.005 \\
\hline Total blood loss (mL) & & 0.259 \\
\hline Age (y) & & 0.078 \\
\hline Gender(male/female) & & 0.479 \\
\hline BMI $\left(\mathrm{kg} / \mathrm{m}^{2}\right)$ & & 0.067 \\
\hline \multicolumn{3}{|c|}{$\Delta C l$, change of coagulation index. BMI, body mass index. OR, odds ratio. TKA, total knee arthroplasty. } \\
\hline \multicolumn{3}{|c|}{$\begin{array}{l}\text { To measure the value of } \mathrm{Cl} \text { and hidden blood loss in predicting the occurrence of ecchymosis, we plotted the } \\
\text { ROC curves of the two variables (Fig. } 1) \text {. } \Delta \mathrm{Cl} \text { discriminated between ecchymosis and nonecchymosis with ar } \\
\text { AUC of } 0.794(95 \% \mathrm{Cl}: 0.730,0.849) \text {. However, hidden blood loss did not exhibit a superior AUC of } 0.681(95 \% \\
\text { Cl: } 0.610,0.746) \text { (Fig. } 1) \text {. }\end{array}$} \\
\hline
\end{tabular}

As shown in Table IV, the threshold of $\mathrm{Cl}$ was 0.1805 , demonstrating a sensitivity of $74.55 \%(95 \% \mathrm{Cl}: 61.0,85.3)$ and a specificity of $72.99 \%(95 \% \mathrm{Cl}: 64.7,80.2)$ for predicting ecchymosis events after TKA. When the amount of hidden blood loss reached $311.63 \mathrm{ml}$ the sensitivity and specificity for predicting the occurrence of ecchymosis were $60.00 \%$ (95\% Cl: 45.9, 73.0) and 76.64\% (95\% Cl: 68.7, 83.4), respectively.

Table IV. Sensitivity, Specificity, PPV and NPV of variables for predicting ecchymosis after TKA. 


\begin{tabular}{|c|c|c|c|c|c|c|c|c|c|}
\hline Parameters & $\begin{array}{l}\text { AUC } \\
(95 \% \mathrm{Cl})\end{array}$ & Cut-off & $\begin{array}{l}\text { Sensitivity } \\
(95 \% \mathrm{Cl})\end{array}$ & $\begin{array}{l}\text { Specificity } \\
(95 \% \mathrm{Cl})\end{array}$ & $\begin{array}{l}\text { PPV } \\
(\%)\end{array}$ & $\begin{array}{l}\text { NPV } \\
(\%)\end{array}$ & LR+ & LR- & $\begin{array}{l}\text { Accuracy } \\
\text { (\%) }\end{array}$ \\
\hline$\Delta \mathrm{Cl}$ & $\begin{array}{l}0.794 \\
(0.730 \\
0.849)\end{array}$ & 0.1805 & $\begin{array}{l}74.55 \\
(61.0 \\
85.3)\end{array}$ & $\begin{array}{l}72.99 \\
(64.7 \\
80.2)\end{array}$ & $\begin{array}{l}52.6 \\
(44.7 \\
60.3)\end{array}$ & $\begin{array}{l}87.7 \\
(81.8, \\
91.9)\end{array}$ & $\begin{array}{l}2.76 \\
(2.0, \\
3.8)\end{array}$ & $\begin{array}{l}0.35 \\
(0.2, \\
0.6)\end{array}$ & 73.4375 \\
\hline $\begin{array}{l}\text { Hidden } \\
\text { blood loss } \\
(\mathrm{mL})\end{array}$ & $\begin{array}{l}0.681(0.610, \\
0.746)\end{array}$ & 311.63 & $\begin{array}{l}60.00 \\
(45.9 \\
73.0)\end{array}$ & $\begin{array}{l}76.64 \\
(68.7, \\
83.4)^{\prime}\end{array}$ & $\begin{array}{l}50.8 \\
(41.5, \\
59.9)\end{array}$ & $\begin{array}{l}82.7 \\
(77.3, \\
87.0)\end{array}$ & $\begin{array}{l}2.57 \\
(1.8, \\
3.7)\end{array}$ & $\begin{array}{l}0.52 \\
(0.4, \\
0.7)\end{array}$ & 71.3542 \\
\hline
\end{tabular}

\section{Discussion}

To our knowledge, this study was the first attempt to use $\Delta \mathrm{Cl}$ to predict ecchymosis events after TKA and demonstrated its reliability. In our cohort, the $\Delta \mathrm{Cl}$ in the ecchymosis group was significantly higher than that in the nonecchymosis group $(p=.001)$ and was an independent risk factor $(O R=0.351, p=.001)$ for ecchymosis after TKA. The optimal cutoff value of $\Delta \mathrm{Cl}(0.1805)$ reflected maximal sensitivity $(74.55 \%)$ and specificity $(72.99 \%)$ to predict ecchymosis events after TKA. This study also found a significant correlation $(\mathrm{OR}=1.003, \mathrm{p}=.005)$ between hidden blood loss and ecchymosis events after TKA. Unfortunately, hidden blood loss showed unsatisfactory sensitivity in predicting the occurrence of ecchymosis events. Hidden blood loss is generally defined as blood deposited in the joint space and blood seeping into the tissue $[16,17]$. However, when the volume of hidden blood loss was not sufficient, the blood in the tissue may have been absorbed by the body before it penetrated the mucosa of the skin, preventing the formation of ecchymosis.

Damage to the vascular wall at the surgical site provides a possibility for the formation of ecchymosis, but it may not be the only cause[18]. The effect of anticoagulants on the formation of ecchymosis cannot be ignored. In the absence of thromboprophylaxis treatment, the incidence of VTE after TKA can be as high as 40-84\%[19]. However, anticoagulant chemoprophylaxis puts patients at risk for bleeding after TKA. Bleeding complications (including ecchymosis) following total joint arthroplasty are not acceptable, as they can lead to more important complications, such as infection, wound healing problems, dysfunction and loosening of the joints, with a high likelihood of affecting the surgical outcome[20]. Rivaroxaban, a direct oral factor Xa inhibitor, is commonly prescribed for the prevention of VTE after TKA due to its effectiveness, high safety and convenience of use[3,21]. However, evidence has shown that rivaroxaban use also increases the risk of postoperative bleeding[7]. This poses a challenge to the balance between anticoagulation and bleeding prevention. Therefore, accurate monitoring of coagulation status and early prediction of ecchymosis events are the key links of individual anticoagulation.

TEG is commonly used to evaluate the viscoelastic properties of a patient's whole blood during surgery [22]. As early as 2009, Jeffry et al.[14] showed the role of TEG in identifying hypercoagulability and predicting thromboembolic events in surgical patients. Previous studies have attempted to apply $\Delta \mathrm{R}$ to adjust the use of anticoagulants, but the data showed that $\Delta \mathrm{R}$ does not have this capability[11]. The possible explanation is that the clotting process involved in the formation of a thrombus or fibrinolysis is complex, and it is unreliable to represent the whole process by a single point of the clotting process. Therefore, in this study, we analyzed and compared the preoperative and postoperative changes in the comprehensive evaluation index $\mathrm{Cl}$. Through the analysis of two cohorts with or without ecchymosis after TKA, we found a high correlation between $\Delta \mathrm{Cl}$ and ecchymosis, which was consistent with previous research results[6]. In addition, we also confirmed that, when the Cl was lower than 
0.1805 , it was a warning that the body was in a hypocoagulable state, and the probability of ecchymosis events was as high as $73.44 \%$.

The patients were prospectively recruited, with each patient followed for at least 2 weeks. The 2-week follow-up covered the entire course of the patient's anticoagulant use, and it was assured that the patient's hemodynamics had stabilized by the end of the follow-up[8].

Some limitations need to be noted in this study. First, this study was performed in a single center, and more regional studies are needed to support our conclusions. We are, in a follow-up study, examining this issue. Second, the patients who underwent TKA were elderly and had different types of underlying diseases. Age and underlying diseases may also be risk factors for the occurrence of ecchymosis[23, 24]. In this study, there was no subgroup analyses on the types of diseases and ages of patients, so the results of the study may be biased. Last, most of the patients were hospitalized for 5 days after surgery. Except for the patients with ecchymosis, blood samples were collected on the day that ecchymosis appeared, and the patients without ecchymosis only had TEG testing during hospitalization. Therefore, it was difficult to ensure that the maximum $\mathrm{Cl}$ in the nonecchymosis group might not be the maximum.

\section{Conclusion}

This study, to our knowledge, is the first to demonstrate that $\Delta \mathrm{Cl}$ in TEG parameters can be used as a predictor of ecchymosis events after TKA, and the optimal cutoff value was 0.1805 . On the basis of our findings, we believe that $\Delta \mathrm{Cl}$ is a promising indicator to guide the use of anticoagulants after TKA. When the $\Delta \mathrm{Cl}$ was lower than 0.1805 , it was reasonable to consider stopping the use of rivaroxaban to avoid the occurrence of ecchymosis events. Of course, more research is needed to verify and confirm the reliability of this prediction.

\section{Abbreviations}

TKA: total knee arthroplasty;

TEG: thromboelastography;

$\mathrm{Cl}$ : coagulation index;

OA: osteoarthritis;

VTE: venous thromboembolism;

HCT: hematocrit;

BMI: body mass index;

AUC: area under the curve;

ROC: receiver operating characteristic

\section{Declarations}

\section{Ethics approval and consent to participate}


The study protocol was approved by the Institutional Review Committee of the First Affiliated Hospital of Chongqing Medical University (IRB No. 2018-028).

\section{Consent for publication}

Patients signed informed consent regarding publishing their data.

\section{Availability of data and materials}

The datasets supporting the results of this article are included within the article and its additional files.

\section{Competing interests}

All authors declare no conflicts of interest.

\section{Funding}

The National Natural Science Foundation of China (82072443).

\section{Authors' contributions}

Ning Hu and Xuan Gong contributed to the experimental ideas and design of this study. Yuelong Chen drafted the manuscript. Leilei Qin collected and analyzed the data. Jiawei Wang performed the statistical analysis. Ning Hu, Xuan Gong examined and revised the contents of the manuscript.

\section{Acknowledgements}

Not applicable

\section{References}

1. Costello CA, Liu M, Furey A, Rahman P, Randell EW, Zhai G (2020) Association Between Epidemiological Factors and Nonresponders to Total Joint Replacement Surgery in Primary Osteoarthritis Patients. The Journal of arthroplasty. DOI 10.1016/j.arth.2020.11.020

2. Kurtz S, Ong K, Lau E, Mowat F, Halpern M (2007) Projections of primary and revision hip and knee arthroplasty in the United States from 2005 to 2030. The Journal of bone and joint surgery American volume 89:780-785. DOI 10.2106/jbjs.f.00222

3. Anderson DR, Dunbar M, Murnaghan J, Kahn SR, Gross P, Forsythe M, Pelet S, Fisher W, Belzile E, Dolan S, Crowther M, Bohm E, MacDonald SJ, Gofton W, Kim P, Zukor D, Pleasance S, Andreou P, Doucette S, Theriault C, Abianui A, Carrier M, Kovacs MJ, Rodger MA, Coyle D, Wells PS, Vendittoli PA (2018) Aspirin or Rivaroxaban for VTE Prophylaxis after Hip or Knee Arthroplasty. The New England journal of medicine 378:699-707. DOI 10.1056/NEJMoa1712746

4. Gould MK, Garcia DA, Wren SM, Karanicolas PJ, Arcelus JI, Heit JA, Samama CM (2012) Prevention of VTE in nonorthopedic surgical patients: Antithrombotic Therapy and Prevention of Thrombosis, 9th ed: American College of Chest Physicians Evidence-Based Clinical Practice Guidelines. Chest 141:e227S-e277S. DOI 10.1378/chest.11-2297 
5. Kakkar AK, Brenner B, Dahl OE, Eriksson BI, Mouret P, Muntz J, Soglian AG, Pap AF, Misselwitz F, Haas S (2008) Extended duration rivaroxaban versus short-term enoxaparin for the prevention of venous thromboembolism after total hip arthroplasty: a double-blind, randomised controlled trial. Lancet (London, England) 372:31-39. DOI 10.1016/s0140-6736(08)60880-6

6. Wang J, Zhu HL, Shi ZJ, Zhang Y (2018) The Application of Thromboelastography in Understanding and Management of Ecchymosis After Total Knee Arthroplasty. The Journal of arthroplasty 33:3754-3758. DOI 10.1016/j.arth.2018.08.024

7. Garfinkel JH, Gladnick BP, Roland N, Romness DW (2018) Increased Incidence of Bleeding and Wound Complications With Factor-Xa Inhibitors After Total Joint Arthroplasty. The Journal of arthroplasty 33:533536. DOI 10.1016/j.arth.2017.08.039

8. Kwong LM, Kistler KD, Mills R, Wildgoose P, Klaskala W (2012) Thromboprophylaxis, bleeding and postoperative prosthetic joint infection in total hip and knee arthroplasty: a comprehensive literature review. Expert opinion on pharmacotherapy 13:333-344. DOI 10.1517/14656566.2012.652087

9. Parvizi J, Ghanem E, Joshi A, Sharkey PF, Hozack WJ, Rothman RH (2007) Does "excessive" anticoagulation predispose to periprosthetic infection? The Journal of arthroplasty 22:24-28. DOI 10.1016/j.arth.2007.03.007

10. Jacobs JJ, Mont MA, Bozic KJ, Della Valle CJ, Goodman SB, Lewis CG, Yates AC, Jr., Boggio LN, Watters WC, 3rd, Turkelson CM, Wies JL, Sluka P, Hitchcock K (2012) American Academy of Orthopaedic Surgeons clinical practice guideline on: preventing venous thromboembolic disease in patients undergoing elective hip and knee arthroplasty. The Journal of bone and joint surgery American volume 94:746-747. DOI 10.2106/JBJS.9408.ebo746

11. Connelly CR, Van PY, Hart KD, Louis SG, Fair KA, Erickson AS, Rick EA, Simeon EC, Bulger EM, Arbabi S, Holcomb JB, Moore LJ, Schreiber MA (2016) Thrombelastography-Based Dosing of Enoxaparin for Thromboprophylaxis in Trauma and Surgical Patients: A Randomized Clinical Trial. JAMA surgery 151:e162069. DOI 10.1001/jamasurg.2016.2069

12. Ågren A, Wikman AT, Holmström M, Östlund A, Edgren G (2013) Thromboelastography (TEG®) compared to conventional coagulation tests in surgical patients-a laboratory evaluation. Scandinavian journal of clinical and laboratory investigation 73:214-220. DOI 10.3109/00365513.2013.765960

13. Tekkesin N, Tekkesin M, Kaso G (2015) Thromboelastography for the monitoring of the antithrombotic effect of low-molecular-weight heparin after major orthopedic surgery. Anatolian journal of cardiology 15:932-937. DOI 10.5152/akd.2014.5723

14. Kashuk JL, Moore EE, Sabel A, Barnett C, Haenel J, Le T, Pezold M, Lawrence J, Biffl WL, Cothren CC, Johnson JL (2009) Rapid thrombelastography (r-TEG) identifies hypercoagulability and predicts thromboembolic events in surgical patients. Surgery 146:764-772; discussion 772-764. DOI 10.1016/j.surg.2009.06.054

15. Gross JB (1983) Estimating allowable blood loss: corrected for dilution. Anesthesiology 58:277-280. DOI 10.1097/00000542-198303000-00016

16. Li B, Wen Y, Liu D, Tian L (2012) The effect of knee position on blood loss and range of motion following total knee arthroplasty. Knee surgery, sports traumatology, arthroscopy: official journal of the ESSKA 20:594-599. DOI 10.1007/s00167-011-1628-4

17. Mylod AG, Jr., France MP, Muser DE, Parsons JR (1990) Perioperative blood loss associated with total knee arthroplasty. A comparison of procedures performed with and without cementing. The Journal of bone and joint surgery American volume 72:1010-1012 
18. Faris PM, Ritter MA, Keating EM, Valeri CR (1991) Unwashed filtered shed blood collected after knee and hip arthroplasties. A source of autologous red blood cells. The Journal of bone and joint surgery American volume 73:1169-1178

19. He ML, Xiao ZM, Lei M, Li TS, Wu H, Liao J (2014) Continuous passive motion for preventing venous thromboembolism after total knee arthroplasty. The Cochrane database of systematic reviews:Cd008207. DOI 10.1002/14651858.CD008207.pub3

20. van der Veen L, Segers M, van Raay JJ, Gerritsma-Bleeker CL, Brouwer RW, Veeger NJ, van Hulst M (2021) Bleeding complications of thromboprophylaxis with dabigatran, nadroparin or rivaroxaban for 6 weeks after total knee arthroplasty surgery: a randomised pilot study. BMJ open 11:e040336. DOI 10.1136/bmjopen-2020040336

21. Eriksson BI, Borris LC, Friedman RJ, Haas S, Huisman MV, Kakkar AK, Bandel TJ, Beckmann H, Muehlhofer E, Misselwitz F, Geerts W (2008) Rivaroxaban versus enoxaparin for thromboprophylaxis after hip arthroplasty. The New England journal of medicine 358:2765-2775. DOI 10.1056/NEJMoa0800374

22. Bai J, Zheng QW, Fu SH, Li XX, Li YR, Zhou Y, Yu JH, Gong ML, Chen DF (2013) Association between thrombelastography system and thromboembolic and bleeding events in Chinese aged people. International journal of clinical and experimental medicine 6:310-319

23. Cao YB, Zhang JD, Shen H, Jiang YY (2010) Rivaroxaban versus enoxaparin for thromboprophylaxis after total hip or knee arthroplasty: a meta-analysis of randomized controlled trials. European journal of clinical pharmacology 66:1099-1108. DOI 10.1007/s00228-010-0889-z

24. Farage MA, Miller KW, Berardesca E, Maibach HI (2009) Clinical implications of aging skin: cutaneous disorders in the elderly. American journal of clinical dermatology 10:73-86. DOI 10.2165/00128071200910020-00001

\section{Figures}




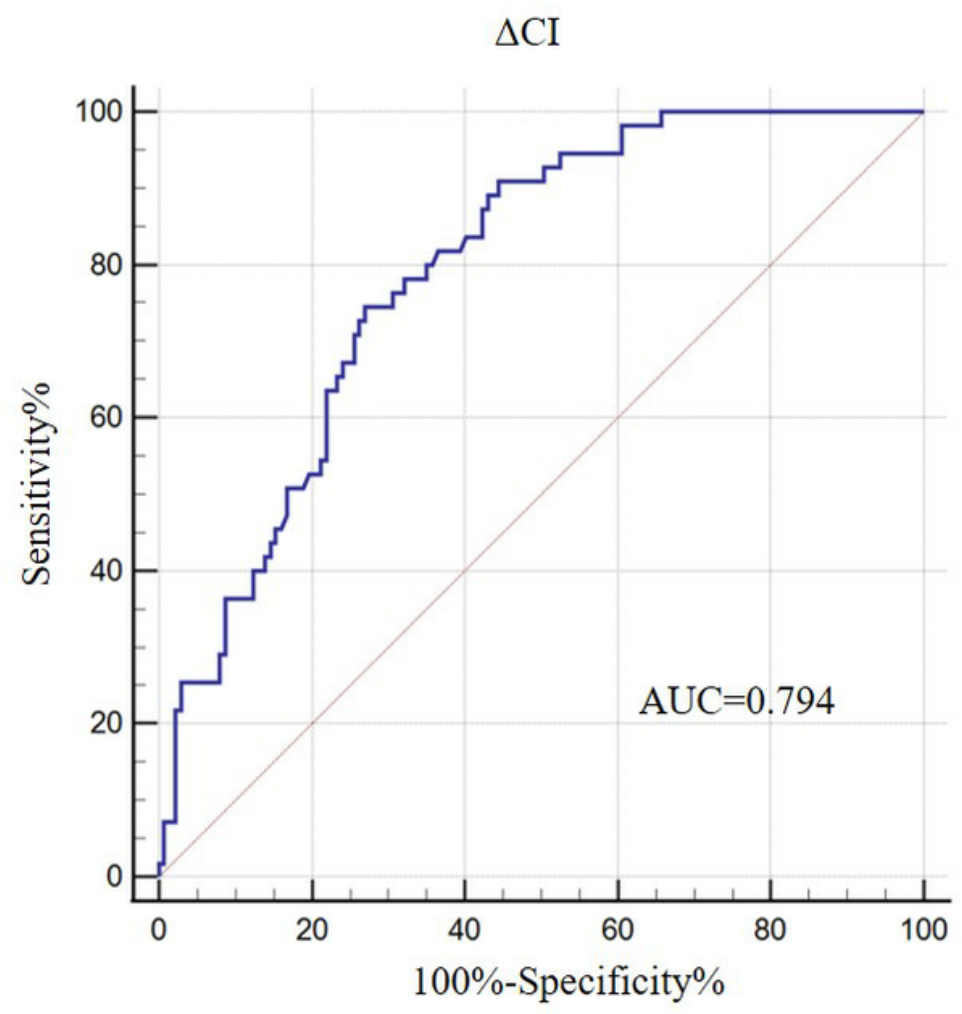

Hidden blood loss

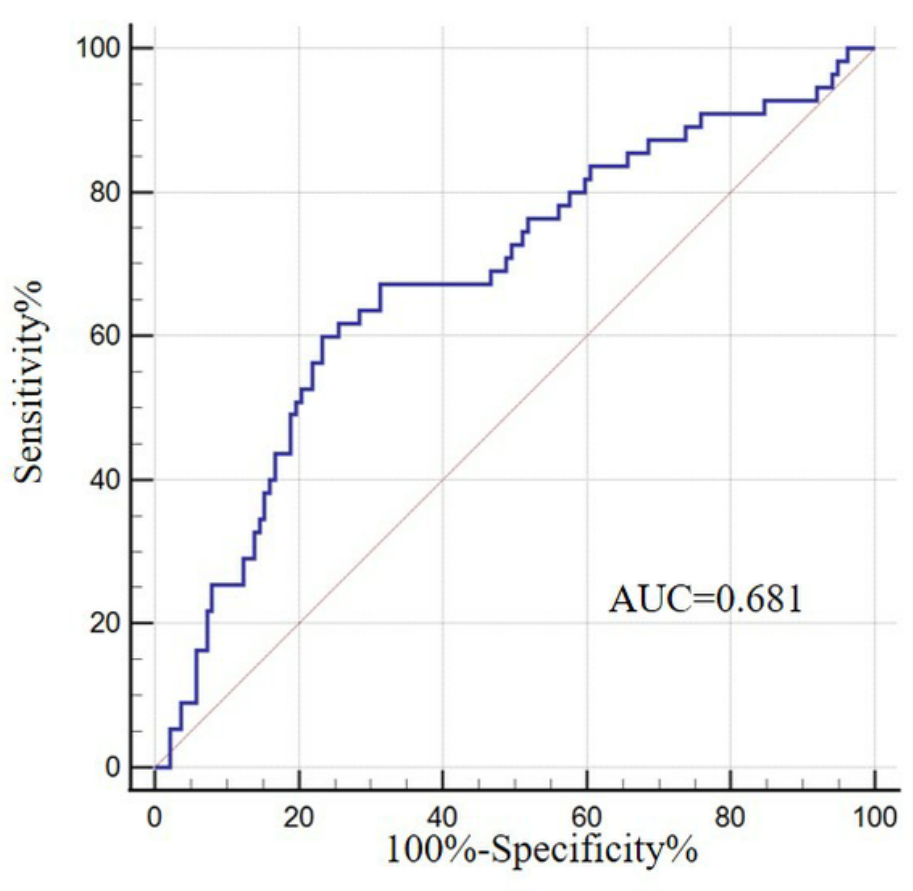

Figure 1 